\section{POS1071 DETERMINATION OF THE RELIABILITY AND VALIDITY OF THE BETY-BIOPSYCHOSOCIAL QUESTIONNAIRE IN PATIENTS WITH A DIAGNOSIS OF PSORIATIC ARTHRITIS}

S. Bulut ${ }^{1}$, E. Ünal2, J. Karakaya ${ }^{3}$, U. Kalyoncu ${ }^{4} .{ }^{1}$ Hacettepe University, Faculty of Physical Therapy and Rehabilitation, Ankara, Turkey; ${ }^{1}$ Hacettepe University, Faculty of Physical Therapy and Rehabilitation, Ankara, Turkey; ${ }^{3}$ Hacettepe University, Faculty of Medicine, Department of Basic Medical Sciences, Ankara, Turkey; ${ }^{4}$ Hacettepe University, Faculty of Medicine, Department of Internal Medical Sciences, Ankara, Turkey

Background: In the literature, there is a lack of questionnaires, which is evaluate patients with psoriatic arthritis (PsA) from a biopsychosocial perspective. Objectives: This study was planned to examine the reliability and validity of the BETY- Biopsychosocial Questionnaire (BQ) in individuals diagnosed with PsA. Methods: Test-retest method was used to examine the reliability of the BETY-BQ. In comparing the reliability of test-retest results, Intraclass coefficient (ICC) was checked. For the internal consistency analysis of the BETY-BQ, the total score of the responses given to the first filled scale was calculated and the Cronbach's Alpha coefficient was found. Psoriatic Arthritis Quality of Life Questionnaire (PsAQoL), Health Assessment Questionnaire (HAQ), Hospital Anxiety and Depression Scale (HADS) and Short Form-36 (SF-36) were used in the validity study of 150 individuals with PsA included in the study.

Results: Test-retest method and intraclass coefficient were examined for reliability analysis (for 30 patients). The correlation $(r=0.844, p<0.001)$ of the answers given to the BETY-BQ by individuals with 30 PsA after one week interval was very high. While the ICC coefficient $(0.915, p<0.001)$ showed excellent reliability. The Cronbach's Alpha coefficient (0.940) was examined for internal consistency and the internal consistency of the scale was also found to be excellent. As a result of statistical analysis, the correlation between the scales used and the BETY-BQ was found between $r=-0.432$ and $0.807(p<0.001)$.

Conclusion: With this study, it was concluded that the BETY-BQ is a reliable and valid assessment tool in individuals diagnosed with PsA, and is also a biopsychosocial tool that can be used to evaluate individuals with PsA.

REFERENCES:

[1] Unal E, Arin G, Karaca Nb, Kiraz S, Akdoğan A, Kalyoncu U, et al. Romatizmalı hastalar için bir yaşam kalitesi ölceginin gelistirilmesi: madde havuzunun olussturulması. Journal of Exercise Theraphy and Rehabilitation. 2017;4(2):67-75

[2] Husni ME, Merola JF, Davin S. The psychosocial burden of psoriatic arthritis. Semin Arthritis Rheum. 2017;47(3):351-60

Disclosure of Interests: None declared.

DOI: 10.1136/annrheumdis-2021-eular.1520

\section{POS1072 ASSOCIATION OF NAIL PSORIASIS WITH WORSE DISEASE OUTCOMES IN PSORIATIC ARTHRITIS PATIENTS. DATA FROM CLINICAL PRACTICE}

E. Gubar ${ }^{1}$, Y. Korsakova ${ }^{1}$, E. Loginova ${ }^{1}$, S. Glukhova ${ }^{2}$, T. Korotaeva ${ }^{1}$,

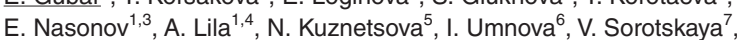
I. Patrikeeva ${ }^{8} .{ }^{1}$ V.A. Nasonova Research Institute of Rheumatology, Spondyloarthritis and psoriatic arthritis, Moscow, Russian Federation; ${ }^{2} V . A$. Nasonova Research Institute of Rheumatology, Medical and Social Problems in Rheumatology, Moscow, Russian Federation; ${ }^{3}$ I.M. Sechenov First Moscow State Medical University, Rheumatology, Moscow, Russian Federation; ${ }^{4}$ Russian Medical Academy of Continuing Professional Education, Rheumatology, Moscow, Russian Federation; ${ }^{5}$ Municipal Autonomous Institution "City Clinical Hospital No. 40", Rheumatology, Yekaterinburg, Russian Federation; ${ }^{6}$ Omsk region "Regional clinical hospital", Rheumatology, Omsk, Russian Federation; ${ }^{7}$ Medical Institute of the Tula State University, Rheumatology, Tula, Russian Federation; ${ }^{8}$ Tyumen Regional Clinical Hospitai №1, Rheumatology, Tyumen, Russian Federation

Background: Limited data are available regarding the burden of nail disease in psoriatic arthritis (PsA). The latest data show that nail involvement in PsA patients (pts) is associated with significantly more severe disease status (1). Objectives: To analyze, in clinical practice, the association of nail psoriasis with disease activity, quality of life, and work productivity in PsA pts.

Methods: 588 pts (M/F-277/311) with PsA according to CASPAR criteria were included in the study. Data were collected from 43 rheumatology clinics from different regions of the Russian Federation. Pts' age $48.6 \pm 0.5$ years (yrs), disease duration $7.0 \pm 0.3 \mathrm{yrs}$. Pts underwent standard clinical examination of PsA activity. Pts were split into two groups (gr.): those with nail psoriasis - gr.1, and those without it - gr.2. Demographics, disease activity, quality of life, and work productivity were compared between pts with and without nail psoriasis using Pearson's chi-square test and Mann-Whitney $\mathrm{U}$ test.

Results: Gr.1 includes 312 (53.1\%) cases, gr.2 - 276 (46.9\%) cases. More pts in gr. 1 were males $(51.9 \%$ vs $44.1 \%, p=0.013)$, disabled at work $(37.20 \%$ vs
$26.40 \%, p=0.000)$, chronic smokers $(18.9 \%$ vs $8.7 \%, p=0.000)$ and with axial PsA disease signs according to physician ( $35.0 \%$ vs $26.4 \%, \mathrm{p}=0.025)$ compared to pts in gr.2. Pts in gr.1 had higher tender and swollen joint counts: 8 [4-15] vs 5 [2-12] $(\mathrm{p}=0.002)$ and $5[1-9]$ vs $2[0-7](\mathrm{p}=0.003)$ respectively. Gr. 1 pts had higher disease activity measured by DAPSA 25 [15-39] vs 20 [12-33] ( $p=0.001)$, highe frequency of dactylitis $(24.4 \%$ vs $16.7 \% \mathrm{p}=0.022)$ and heel enthesitis $(17.0 \%$ vs $10.1 \% \mathrm{p}=0.016)$ respectively, higher frequency of erosive radiographic arthritis of feet $(45.0 \%$ vs $31.2 \% \mathrm{p}=0.003)$ compared to gr. 2 pts. Pts in gr. 1 had worse skin psoriasis measured by Psoriasis Area Severity Index - 6 [2-14] vs 3 [1-6] $(p=0.000)$. Less pts in gr. 1 than in gr. $2(27.0 \%$ vs $52.0 \% p=0.004)$ achieved minimal disease activity (MDA). Pts' reported outcomes (PRO's) in gr.1 were worse than in gr.2 in regard to reduced health-related quality of life according to PSAID $(4.9 \pm 2.3$ vs $4.0 \pm 2.3, p=0.040)$ and to $E Q-5 D(0.56 \pm 0.19$ vs $0.64 \pm 0.21, p=0.024)$ questionnaires, overall work impairment $(0.0[0.0-0.3]$ vs $0.0[0.0-0.2], p=0.034)$ and overall activity impairment $(0.4[0.1-0.7]$ vs $0.3[0.0-0.5], p=0.006)$ according to WPAI.

Conclusion: Nail involvement in PsA pts is associated with male gender and axial disease. PsA pts with nail involvement are more often disabled, more often are chronic smokers, have significantly worse disease status as measured by disease activity; they are more likely to have more severe (erosive) peripheral arthritis of feet, higher frequency of heel enthesitis and dactylitis, higher psoriasis disease severity, lower frequency of MDA achievement, and worse quality of life and work productivity according to PRO's. Detection of nail involvement is critical for choice of treatment approach and better outcomes.

\section{REFERENCES:}

[1] Mease PJ et al.J Rheumatol, 2020

Disclosure of Interests: None declared.

DOI: 10.1136/annrheumdis-2021-eular.1576

\section{POS1073 \\ AXIAL PSORIATIC ARTHRITIS AND ANKYLOSING SPONDYLITIS. SAME OR DIFFERENT? A REAL- WORLD STUDY WITH EMPHASIS ON COMORBIDITIES}

G. E. Fragoulis ${ }^{1}$, M. Pappa ${ }^{1}$, G. Evangelatos ${ }^{1}$, A. Iliopoulos ${ }^{2}$, P. Sfikakis ${ }^{1}$, M. Tektonidou' ${ }^{1}$ National and Kapodistrian University of Athens, First Department of Propaedeutic Internal Medicine, Joint Rheumatology Program, Athens, Greece; ${ }^{2} 417$ Army Shared Fund Hospital "NIMTS", Department of Rheumatology, Athens, Greece

Background: Axial involvement affects $25-70 \%$ of psoriatic arthritis (PsA) patients, depending on the criteria used for its definition. Efforts are underway to clarify the similarities and differences between axial-PsA and ankylosing spondylitis (AS)

Objectives: We aimed to compare, in a real-world setting, axial-PsA and AS, in terms of demographic, radiologic and clinical (musculoskeletal and extra-articular) characteristics, with a focus on comorbidities.

Methods: All AS (New York criteria, $\mathrm{n}=128$ ) and PsA patients (CASPAR criteria, $n=78$ ) with axial involvement who were regularly followed-up in the outpatients' rheumatology clinics from two tertiary hospitals (December 2018-July 2020) were included. Axial-PsA was defined when both of the following were ever present: inflammatory axial symptoms and radiological findings in X-ray or MRI of the sacroiliac joints or the spine. The following findings were considered: sacroiliitis (unilateral $\geq$ grade 3 or bilateral $\geq$ grade 2), corner lesions or squaring in the vertebrae, syndesmophytes (marginal or para-marginal) and facet joints arthritis.

Demographic, radiologic and clinical characteristics including comorbidities were compared between AS and axial-PsA. For comorbidities (Major Adverse Cardiovascular Events [MACE: combined coronary disease and cerebrovascular accidents], hypertension, diabetes mellitus, dyslipidemia, depression, osteoporosis, and malignancies), adjustments were made for relevant confounders as follows: MACE were adjusted for: age, gender, smoking, hypertension, dyslipidemia, disease duration, DM and non-steroidal anti-inflammatory drugs [NSAIDs] use; depression for: age, gender and disease duration; malignancy for: age, gender, disease duration; hypertension for: age, sex, BMI, NSAIDs use, smoking for; DM: age, sex, BMI, glucocorticoids treatment; osteoporosis for: age, sex, glucocorticoids treatment. Statistical significance is considered for $\mathrm{p}$-values less than 0.05 and 0.1 in univariate and multivariate analyses, respectively.

Results: AS patients were younger $(p=0.05)$ and were diagnosed at a younger age $(p=0.002)$, more frequently of male gender $(p=0.04)$, had lower BMI $(p=0.006)$ and they were more frequently HLA-B27-positive $(p=0.006)$. In AS patients, peripheral arthritis, dactylitis and nail involvement were less common $(p=0.001$ for all), in contrast to eye $(p=0.001)$ and bowel involvement $(p=0.004)$. Frequency of radiologic abnormalities in the spine was similar between the two groups while sacroiliitis was more often bilateral in AS and unilateral in axial-PsA ( $p<0.001$ for both) Comorbidities, including MACE, were comparable between AS and axial-PsA, apart from depression which was more frequent in axial-PsA (Table 1. next page). 